\title{
Large Eddy Simulation of a
}

Premixed Flame in Hot Vitiated

Crossflow With Analytically

\section{Reduced Chemistry}

\section{Conference Paper}

Author(s):

Schulz, Oliver; Noiray, Nicolas

Publication date:

2018

Permanent link:

https://doi.org/10.3929/ethz-b-000323363

Rights / license:

In Copyright - Non-Commercial Use Permitted

Originally published in:

4B, https://doi.org/10.1115/GT2018-77115

Funding acknowledgement:

160579 - Tomorrow's Sequential Combustion Technologies for Low Emissions and High Fuel Flexibility (SNF) 


\title{
Large eddy simulation of a premixed flame in hot vitiated crossflow with analytically reduced chemistry
}

\author{
Oliver Schulz* \\ CAPS Laboratory \\ Department of Mechanical and Process Engineering, ETH Zurich \\ 8092 Zurich, Switzerland \\ Email: oschulz@ethz.ch \\ Nicolas Noiray \\ CAPS Laboratory \\ Department of Mechanical and Process Engineering, ETH Zurich \\ 8092 Zurich, Switzerland \\ Email: noirayn@ethz.ch
}

\begin{abstract}
This numerical study deals with a premixed ethylene-air jet at $300 \mathrm{~K}$ injected into a hot vitiated crossflow at 1500 $K$ and atmospheric pressure. The reactive jet in crossflow (RJICF) was simulated with compressible 3-D large eddy simulations (LES) with an analytically reduced chemistry $(A R C)$ mechanism and the dynamic thickened flame (DTF) model. ARC enables simulations of mixed combustion modes, such as autoignition and flame propagation, that are both present in this RJICF. O-D and 1-D simulations provide a comparison with excellent agreement between ARC and detailed chemistry in terms of autoignition time and laminar flame speed. The effect of the DTF model on autoignition was investigated for varying species compositions and mesh sizes. Comparisons between LES and experiments are in good agreement for average velocity distributions and jet trajectories; LES remarkably capture experimentally observed flame dynamics. An analysis of the simulated RJICF shows that the leeward propagating flame has a stable flame root close to the jet exit. The lifted windward flame, on the contrary, is anchored in an intermittent fashion due to autoignition flame stabilization. The windward flame base convects downstream and is "brought back" by autoignition alternately. These autoignition events occur close to a thin layer that is associated with radical build-up and that stretches down to the jet exit.
\end{abstract}

\section{Introduction}

Jets in crossflow (JICF) have been studied extensively for more than 8 decades [1,2]. They are employed, for example, in modern combustion systems for aeronautic and power applications (e.g. [3,4]) for fuel or dilution air injection providing fast mixing between the streams. One can refer to [5] for a recent review about JICF.

In contrast, much less is known about reactive jets in crossflow (RJICF) [6], although early works date back to the 1970s [7,8]. In recent studies, Wagner et al. [9-11] investigated a premixed ethylene-air jet into hot vitiated crossflow experimentally. The authors simultaneously performed hydroxide $(\mathrm{OH})$ and formaldehyde $\left(\mathrm{CH}_{2} \mathrm{O}\right)$ planar laser-induced fluorescence (PLIF) and particle image velocimetry. Building upon these experimental studies, this numerical paper aims at bringing more insight into the flame dynamics and stabilization mechanisms.

Different types of RJICF have been investigated experimentally and numerically. For experiments with an ignitable mixture in the jet (premixed), one can refer to $[13,14]$. The number of experiments with pure fuel inside the jet (non-premixed) is significantly higher, for example [15-19]. Other non-premixed experimental works discuss autoignition as a flame stabilization mechanism. Sullivan et al. [20] injected different fuels in high temperature cross flows $\left(T_{\mathrm{cf}}=1775 \mathrm{~K}\right)$. The measured

\footnotetext{
*Address all correspondence to this author.
}

$\dagger$ Address all correspondence to this author. 

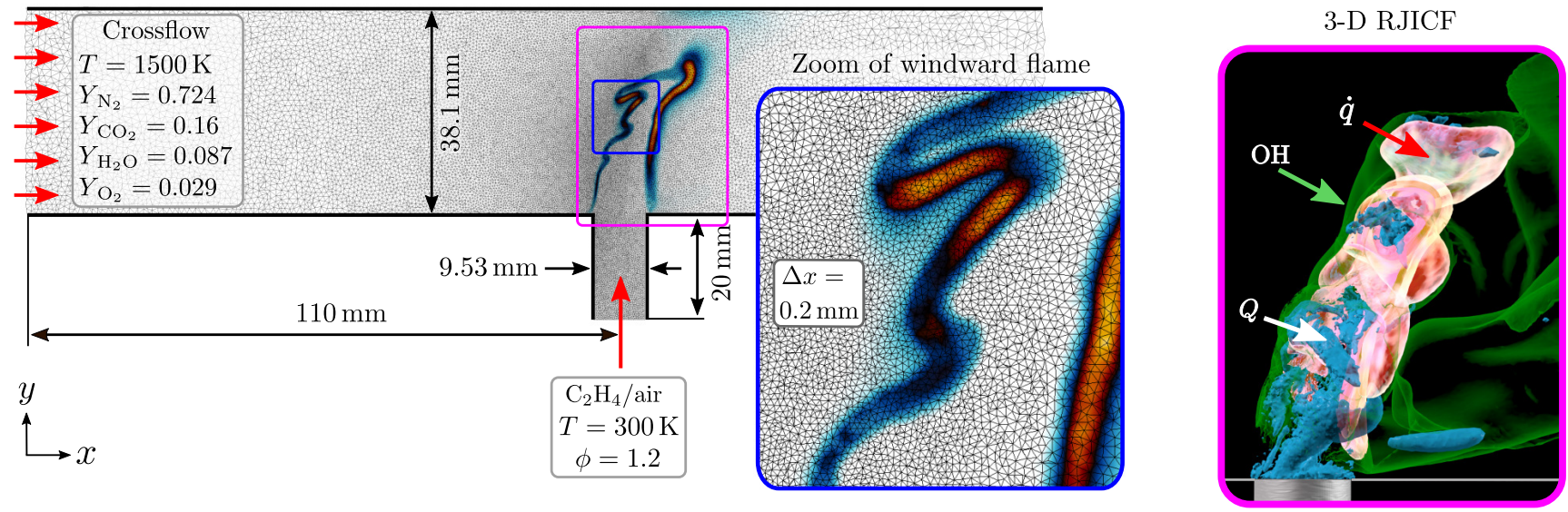

Fig. 1. Computational mesh, boundary conditions and dimensions for the 3-D reactive jet in crossflow LES. Experimental configuration was introduced and investigated in [9-11]. Mesh overlaid with instantaneous heat release rate $\dot{q}$ contour. The total number of cells is 11 million. 3-D rendering of isosurfaces of heat release rate $\dot{q}$, hydroxide $\mathrm{OH}$ mass fraction and Q-criterion [12] $Q$ visualizing vortical structures.

ignition locations were of the same order of magnitude as locations computed with 0-D reactor simulations and jet velocities. Therefore, the authors proposed autoignition as a stabilization mechanism. Experimental ignition locations of Fleck et al. [21] $\left(T_{\mathrm{cf}}=1143 \mathrm{~K}\right.$ and $\left.1185 \mathrm{~K}\right)$, on the contrary, were one order of magnitude smaller than 0-D values. Another work [22] $\left(T_{\mathrm{cf}}=1364 \mathrm{~K}\right)$ proposed a combination of three distinct combustion regimes for flame stabilization: upstream autoignition, premixed and non-premixed flames. These examples show that there are still open questions about the dominant flame stabilization mechanism for RJICF.

In experiments, it is often difficult or not even possible to analyze flow regions where autoignition is initialized [23]. Autoignition occurs at the most reactive mixture fraction [24], which is the mixture composition with the shortest autoignition time. Often, these mixtures are associated with very low fuel concentrations [25] that cannot be tracked. On the contrary, numerical simulations give access to such critical flow regions, provided that the dominant combustion modes are modeled correctly. For example, RJICF were simulated using large eddy simulations (LES) with one step chemistry $\left(T_{\mathrm{cf}}=1773 \mathrm{~K}\right)$ in [26] and a hybrid Eulerian/Lagrangian approach with single step chemistry $\left(T_{\mathrm{cf}}=473 \mathrm{~K}\right)$ in [27].

Single step (and also two to four step) chemistry mechanisms are empirically reduced mechanisms [28] that are tuned to match global flame properties. For example, the scheme presented in [29] predicts the adiabatic flame temperature $T_{\text {ad }}$ and the burning velocity $s_{\mathrm{L}}$ over a wide range of equivalence ratios; the mechanism in [30] predicts $T_{\text {ad }}$ and autoignition delays $\tau_{\mathrm{AI}}$ for one "design point". For the present configuration, experimental results [9-11] indicated that both autoignition and flame propagation are likely to play a key role in the flame stabilization mechanisms. In order to model a mix of different combustion modes, a global mechanism is not suitable. An alternative is the tabulated flamelet approach [31] which was successfully applied to autoignition flames in combination with a stochastic fields turbulence-chemistry interaction model [32]. For more practical applications [33] however, one drawback of tabulated chemistry is the augmented complexity of the lookup table. For example, main air, cooling air and dilution air at varying inlet temperatures, and fuel injection with varying compositions/fuels can lead to four or five mixing streams. Additionally, to capture the impact of pressure [34] and strain, more dimensions need to be added to the look-up table. Hence, the computing time considerably increases [28], and simulations can become computationally unfeasible due to such high numbers of dimensions. Another alternative is an analytically reduced chemistry (ARC) mechanism (e.g. $[19,25,35,36])$. A comparison between the tabulated chemistry approach (e.g. five transported scalars) and the ARC mechanism, used in this study [35] (18 transported species), gives an increase of computational costs for ARC by a factor of approximately 2.3. Nevertheless, ARC allows to simulate a great number of mixing streams, and accounts for pressure and strain effects on autoignition and flame propagation.

This work, for the first time, uses LES with ARC to investigate the flame dynamics and flame stabilization of a premixed ethylene-air jet in hot vitiated crossflow $\left(T_{\mathrm{cf}}=1500 \mathrm{~K}\right)$, which was examined experimentally by Wagner et al. [9-11]. In the first section of this paper, the geometry and the boundary conditions of the investigated RJICF are presented, together with the numerical methods for the simulation: LES, ARC and the combustion model. This section also investigates the effect of the dynamic thickened flame (DTF) model on autoignition and provides a discussion on the turbulence-chemistry interaction. Second, a comparison of ARC with detailed chemistry is shown with results from 0-D reactors and 1-D flames. Then, results from LES are compared to experiments by considering jet trajectories, average velocity fields and instantaneous fields. Finally, the flame dynamics and stabilization mechanism of the RJICF are analyzed. 
(a)

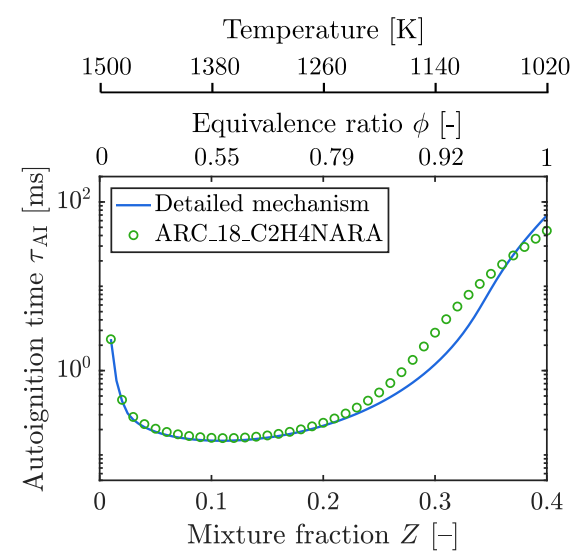

(b)

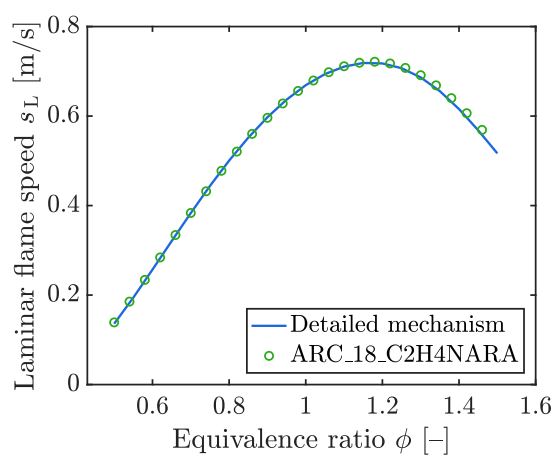

(c)

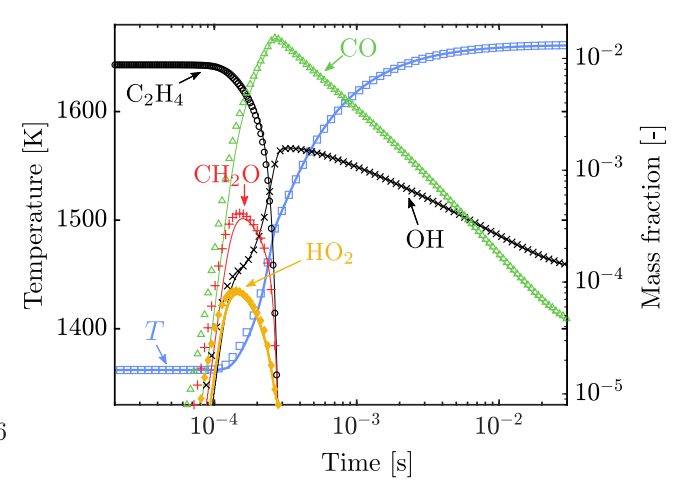

Fig. 2. Comparison between detailed chemistry [37] and analytically reduced chemistry (ARC_18_C2H4NARA) at 1 bar. (a) shows autoignition times $\tau_{\mathrm{AI}}$ obtained from 0-D reactor simulations with Cantera [38]. Mixture fraction $Z$ describes mixing between hot crossflow at $1500 \mathrm{~K}$ $(Z=0)$ and the cold premixed ethylene-air jet at $300 \mathrm{~K}(Z=1)$. Two additional axis show equivalence ratio $\phi$ and mixing temperature. (b) shows laminar flame speeds $s_{\mathrm{L}}$ obtained from 1-D flame simulations using Cantera; fresh gas temperature at $300 \mathrm{~K}$. (c) shows temperature (left) and species mass fraction (right) profiles for a $0-D$ reactor simulation at most reactive $Z(\phi \approx 0.55)$. Symbols and lines show ARC_18_C2H4NARA and detailed chemistry.

\section{Configuration and methodology The RJICF configuration}

Figure 1 shows an $x-y$ cut of the computational domain with a rectangular cross-section (length $190 \mathrm{~mm}$, width $76.2 \mathrm{~mm}$ and height $38.1 \mathrm{~mm}$ ) for the RJICF simulations. The experiments at atmospheric pressure were conducted by Wagner et al. [9-11]. The distance between the inlet and the fuel injector is equivalent to the distance between flow straightener and fuel injection in the experiment. Besides the crossflow bulk velocity $u_{\mathrm{cf}}=7.6 \mathrm{~m} / \mathrm{s}$, no information about neither the velocity profile nor turbulence intensity was given in the experimental studies. The subscript "cf" and "j" denote crossflow and jet respectively. The hot crossflow was generated in the experiments by a propane/air flame with an equivalence ratio $\phi=0.87$. We computed a 1-D flame with Cantera [38] using detailed chemistry [37] and obtained the inlet mixture composition that is shown in Fig. 1. A crossflow temperature of $1500 \mathrm{~K}$ was measured along a lateral span at the jet exit location by a suction pyrometer with a thermocouple to minimize errors due to high-temperature radiation [9]; the non-uniformity was $\pm 15 \mathrm{~K}$.

The premixed ethylene-air jet with $\phi=1.2$ at $300 \mathrm{~K}$ was injected through a fuel pipe with a diameter $d=9.53 \mathrm{~mm}$. The jet bulk velocities $u_{\mathrm{j}}=9.96 \mathrm{~m} / \mathrm{s}$ and $u_{\mathrm{j}}=7.7 \mathrm{~m} / \mathrm{s}$ were computed based on the given jet-to-crossflow momentum ratios $J$ of 8.7 and 5.2 respectively. The ratio is defined as $J=\left(\rho_{\mathrm{j}} u_{\mathrm{j}}^{2}\right) /\left(\rho_{\mathrm{cf}} u_{\mathrm{cf}}^{2}\right)$. The length of the pipe in the experiment is $\approx 33 d$; particle image velocimetry measurements showed a fully developed turbulent flow profile [11].

\section{Analytically reduced chemistry (ARC)}

The LES was performed with an ARC mechanism that was recently derived by Felden et al. [35] from the detailed scheme of Narayanaswamy et al. [37] (164 transported species) tailored for ethylene-air combustion. The ARC mechanism (18 transported species) is referred to as ARC_18_C2H4NARA below. A two-step reduction procedure was carried out utilizing the reduction tool YARC [39,40]. First, species and reactions reduction lead to a skeletal mechanism with 29 species. Second, to further reduce the skeletal mechanism, a quasi-steady-state approximation was applied to 11 species, resulting into ARC_18_C2H4NARA that comprises these 18 transported species: $\mathrm{N}_{2}, \mathrm{H}, \mathrm{H}_{2}, \mathrm{O}, \mathrm{OH}, \mathrm{O}_{2}, \mathrm{H}_{2} \mathrm{O}_{2}, \mathrm{H}_{2} \mathrm{O}, \mathrm{HO}_{2}$, $\mathrm{CO}, \mathrm{CH}_{3}, \mathrm{CH}_{2} \mathrm{O}, \mathrm{CO}_{2}, \mathrm{CH}_{4}, \mathrm{C}_{2} \mathrm{H}_{2}, \mathrm{C}_{2} \mathrm{H}_{4}, \mathrm{C}_{2} \mathrm{H}_{6}$ and $\mathrm{CH}_{2} \mathrm{CO}$.

Figure 2a compares autoignition times for two chemical mechanisms: the detailed mechanism [37] and the ARC mechanism used in this study. The autoignition time $\tau_{\mathrm{AI}}$ is shown in logarithmic scale over mixture fraction $Z$. $\tau_{\mathrm{AI}}$ was obtained from $0-$ $D$ reactor simulations using Cantera and it is defined at the highest temperature gradient. $Z$ describes the mixing between the hot crossflow at $1500 \mathrm{~K}(Z=0)$ and the cold premixed ethylene-air jet at $300 \mathrm{~K}(Z=1)$, without chemical reactions between fuel and oxidizer. Each $Z$ value corresponds to one species composition or equivalence ratio $\phi$, and mixing temperature, both shown with two additional axes. ARC_18_C2H4NARA and the detailed mechanism are in very good agreement. Both predict the most reactive mixture fraction $Z_{\mathrm{mr}}$, which is the $Z$ with the shortest autoignition time, at $\approx 0.11$.

Figure $2 \mathrm{~b}$ compares laminar flame speeds $s_{\mathrm{L}}$ over equivalence ratio $\phi$ for the same two chemical mechanisms presented in (a). These results were obtained from 1-D freely-propagating flame simulations using Cantera. The fresh gas temperature was set to $300 \mathrm{~K}$ for all $\phi$. Results for ARC_18_C2H4NARA and the detailed scheme are in excellent agreement. Figure 2c 

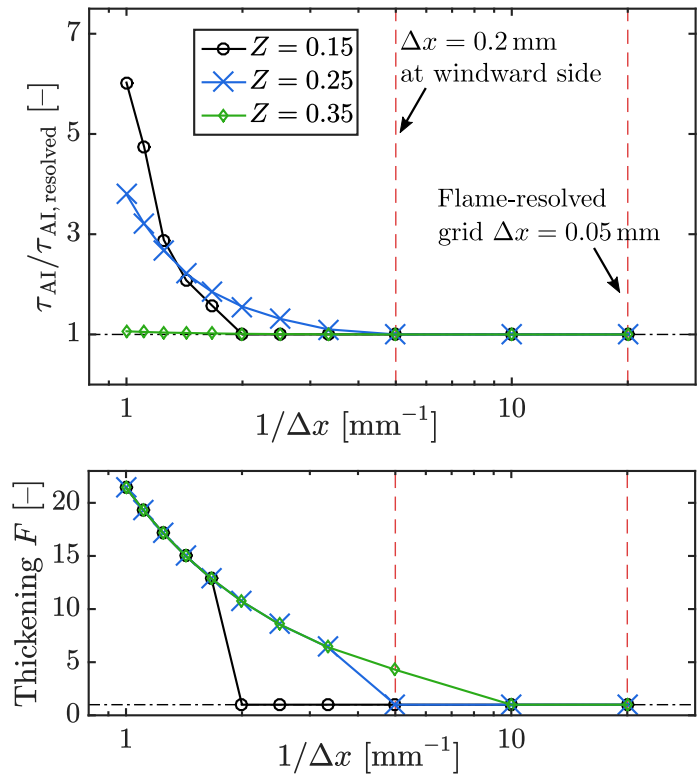

Fig. 3. The effect of the dynamic thickened flame (DTF) model on the onset of autoignition. Top: autoignition time $\tau_{\mathrm{AI}}$ normalized by autoignition time obtained on a flame-resolved grid (right vertical dashed line) $\tau_{\mathrm{AI}}$, resolved for three mixture fractions $Z$. Bottom: thickening factors $F$ applied by the DTF model. Results obtained by 0-D reactor simulations (symbols) with AVBP. The left vertical dashed line shows grid resolution on the windward side of the RJICF.

shows temperature and species mass fraction profiles obtained with Cantera 0-D reactor simulations using the two schemes. The mechanisms are in excellent agreement; both predict a thin region of formaldehyde $\mathrm{CH}_{2} \mathrm{O}$ and hydroperoxyl $\mathrm{HO}_{2}$ just before the temperature increases suddenly.

\section{Large eddy simulations (LES)}

Compressible reactive LES were performed using the explicit cell-vertex code AVBP [41] with the step Taylor-Galerkin scheme TTGC [42] giving third-order accuracy in space and time. The classical Smagorinsky approach was used to model the Reynolds sub-grid scale stress tensor. The time step of $5 \times 10^{-8} \mathrm{~s}$ is based on the acoustic CFL condition. At the inlets and the outlet, we used Navier-Stokes characteristic boundary conditions (NSCBC). We imposed a flat velocity profile without turbulence at the crossflow inlet and simulated the entire distance of $110 \mathrm{~mm}$ between flow straightener and jet. The crossflow temperature was set to $1500 \mathrm{~K}$.

A mean profile of a fully developed turbulent pipe flow with isotropic turbulence (intensity $u^{\prime} / u_{\mathrm{j}}=0.1$ ) was imposed at the jet inlet. A priori simulations with and without fuel pipe showed a non-negligible change in jet trajectories. Simulations were performed for different lengths of the jet pipe. No change in jet trajectory was observed for pipe lengths of $2 d$ and $4 d$, and therefore, the simulated pipe length is $2 d$.

No information about wall boundary conditions, such as wall temperature was available from the experiments. In the LES, heat loss $\dot{q}=\left(T_{\text {wall }}-T_{\infty}\right) / R_{\mathrm{w}}$ was imposed at the domain walls, with reference temperature $T_{\infty}=300 \mathrm{~K}$ and thermal resistance $R_{\mathrm{W}}=0.02 \mathrm{~K} / \mathrm{W}$. This led to wall temperatures $T_{\text {wall }}$ of approximately $700 \mathrm{~K}$.

The unstructured computational grid, which has a total number of 11 million tetrahedral cells, is presented in Fig. 1. A first estimation of the required mesh resolution was done based on the LES filter size $\Delta$. Pope [43] showed that at least $80 \%$ of the turbulent kinetic energy should be resolved; a ratio between filter width and integral length scale $\left(\Delta / L_{\mathrm{t}}\right)$ of approximately 0.083 would resolve $80 \%$ of the turbulent kinetic energy [43]. $L_{\mathrm{t}}$ is of the order of the largest eddies in the domain and was estimated as $4.8 \mathrm{~mm}$, which is half the diameter of the fuel injector pipe. Using Pope's criterion, a filter width of $\Delta \approx 0.4 \mathrm{~mm}$ was computed. This is just a first estimation and the choice of integral length scale might appear to be somewhat arbitrary. Therefore, we performed LES on four different meshes with characteristic cells sizes of $0.2 \mathrm{~mm}, 0.3 \mathrm{~mm}, 0.5 \mathrm{~mm}$ and $1 \mathrm{~mm}$. For all four meshes, we observed grid independence with regard to average jet trajectories. However, for average velocity magnitudes along the trajectories, grid independence was reached only for $\Delta x=0.2 \mathrm{~mm}$ and $0.3 \mathrm{~mm}$. Hence, we used a grid size of $\Delta x=0.3 \mathrm{~mm}$ in the leeward side of the jet. Moreover, we deployed a coupled velocity/temperature wall-model that is based on the Van Driest formulation [44] and the extension of Schmitt et al. [45], which is suitable for non-isothermal configurations.

The flame thickness for a 1-D propagating flame at $\phi=1.2$ and a fresh gas temperature of $300 \mathrm{~K}$ is approximately $0.25 \mathrm{~mm}$. A cell size of $\approx 0.06 \mathrm{~mm}$ would discretize the flame front with $4-5$ cells. This, however, would increase the cell count 


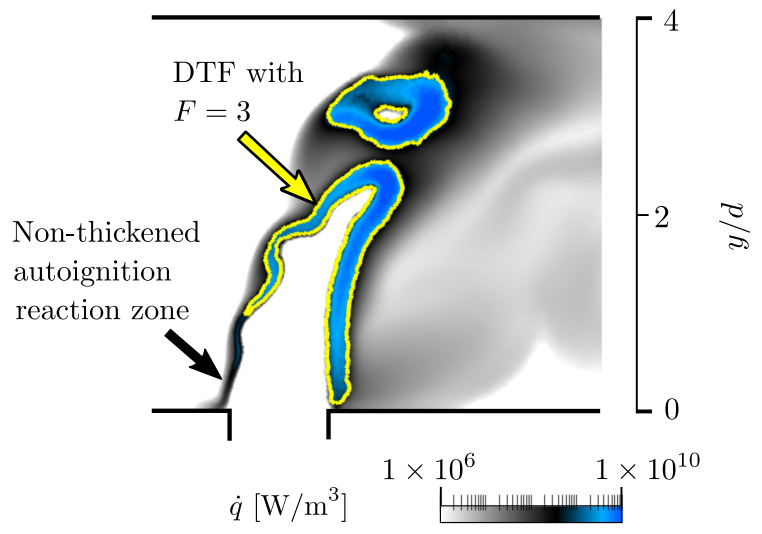

Fig. 4. Heat release rate $\dot{q}$ contour overlaid with isoline at thickening factor $F=3$ (yellow). This highlights regions where the DTF model applies flame thickening.

(a)

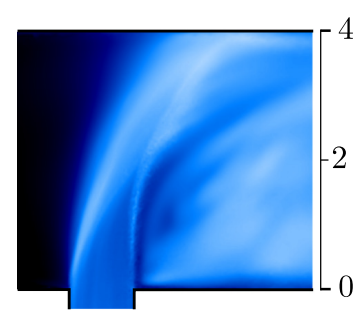

$$
k_{\mathrm{re}}+k_{\mathrm{sgs}}\left[\mathrm{kg} \mathrm{m}^{2} / \mathrm{s}^{2}\right]
$$

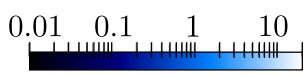

(b)
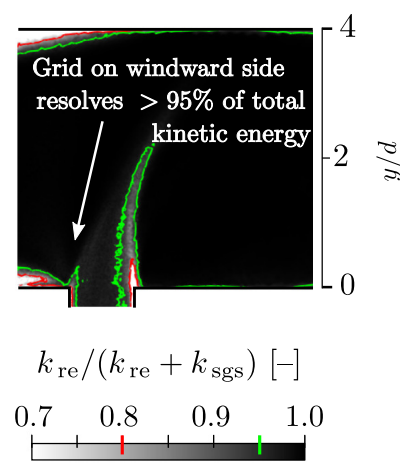

Fig. 5. (a) contour of total kinetic energy that is composed of the resolved part of the turbulent kinetic energy $k_{\text {re }}$ and the modeled sub-grid energy $k_{\mathrm{sgs}}$. (b) the ratio between $k_{\mathrm{re}}$ and total kinetic energy.

by a factor of approximately 37. Moreover, the LES time step would decrease, both leading to a significant increase of computational costs. Therefore, the turbulence/ flame interaction was modeled with the dynamic thickened flame (DTF) model which has been proven to perform well in endless studies, e.g. [19, 25, 28, 29,35,46]. The model thickens the flame front to a minimum of 4.5 cells while maintaining the correct laminar flame speed of $0.73 \mathrm{~m} / \mathrm{s}$. The sub-grid scale flame wrinkling was modeled with the efficiency function of Colin et al. [46]. The effect of the DTF on autoignition is an open question at the moment; in [25] it was shown that flame thickening can delay the onset of autoignition. Therefore, Fig. 3 investigates the influence of the DTF model on autoignition times $\tau_{\mathrm{AI}}$ for varying grid size $\Delta x$ at three mixture fractions $Z$. $\tau_{\mathrm{AI}}$ is normalized by the autoignition time that was obtained on a flame-resolved grid $\tau_{\mathrm{AI}}$, resolved $\Delta x=0.05 \mathrm{~mm}$. The bottom plot shows the corresponding thickening factors $F$ applied by the DTF model. The DTF parameters for the 0-D reactor simulations were the same as in the actual RJICF simulation. For a grid size of $1 \mathrm{~mm}$ and $Z=0.15$, thickening factors of 21 are applied and $\tau_{\mathrm{AI}}$ is delayed up to a factor of 6. It is also shown that the DTF model does not delay the onset of autoignition for the characteristic mesh size of the windward flame $(\Delta x=0.2 \mathrm{~mm})$, which is highlighted with the left vertical dashed line. Indeed, as shown in an instantaneous snapshot of heat release rate $\dot{q}$ contour in Fig. 4, flame thickening (yellow isoline) is only applied in the high heat release rate region of the propagating upper windward flame and the leeward flame, but not in the lower windward reaction zone that is associated with autoignition chemistry. In this zone, the flame-turbulence interaction is not modeled by the DTF model. Therefore, a posteriori, we computed the ratio between the resolved scales and the total fluctuating energy. Figure 5a shows the total kinetic energy that is composed of a resolved part $k_{\mathrm{re}}$ and the non-resolved sub-grid energy $k_{\mathrm{sgs}}$, which was computed using $1 /\left(C_{\mathrm{V}} \Delta\right)^{2} \mathrm{v}_{t}^{2}$ [47] with constant $C_{\mathrm{V}}=0.17$ and eddy viscosity $v_{t}$. (b) shows the ratio between $k_{\text {re }}$ and total kinetic energy. In the region of interest, the modeled scales contribute less than $2 \%$ to the total kinetic energy and therefore, the sub-grid turbulence-chemistry interaction in the autoignition driven reaction zone is neglected for this study. 


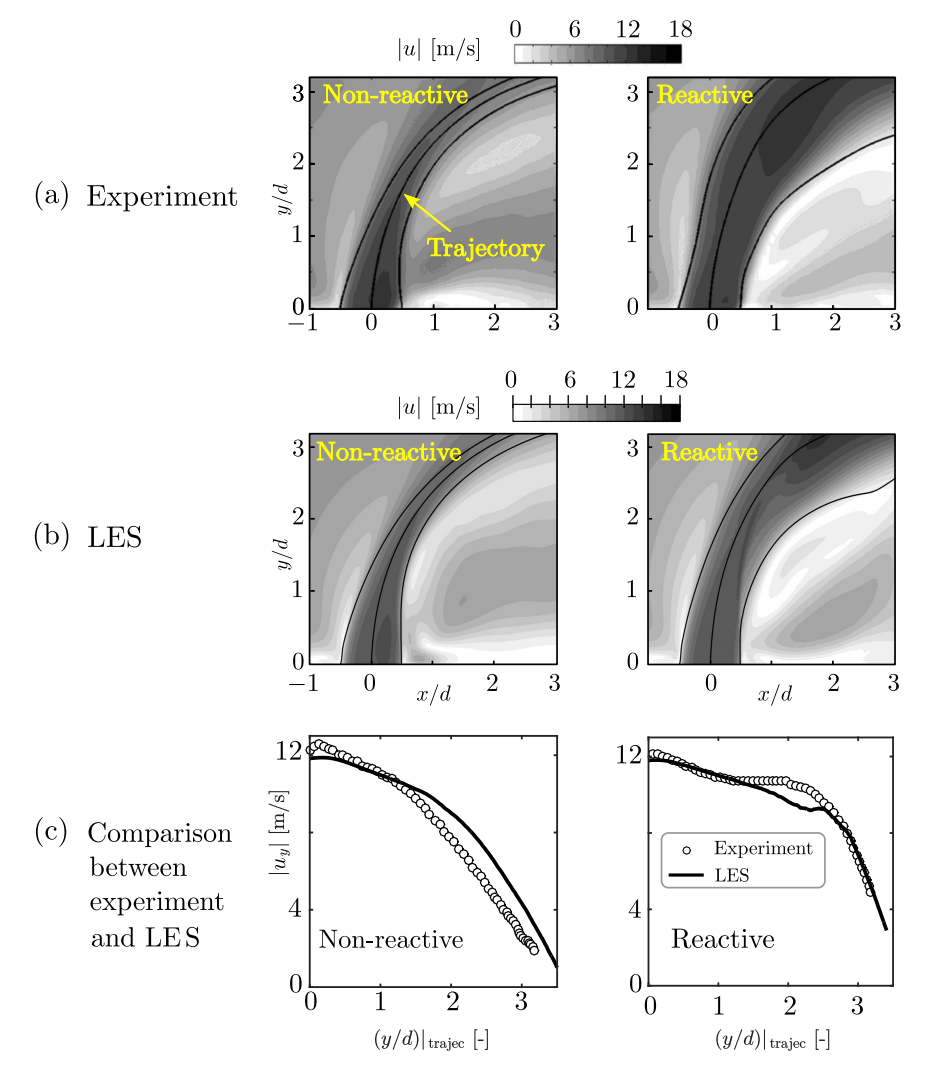

Fig. 6. Experimental [11] (a) and LES (b) contours of velocity magnitude $|u|=\sqrt{u_{x}^{2}+u_{y}^{2}}$ in the central plane for non-reactive (left) and reactive (right) jets in crossflow. Solid lines show streamlines originating at the windward jet edge, the jet center, and the leeward jet edge. (c) shows velocity magnitude $\left|u_{y}\right|$ along normalized $y$-coordinate of jet-center trajectory. Jet-to-crossflow momentum ratio $J=8.7$.

\section{Comparison to experiments}

Figure 6a and $\mathrm{b}$ show the average velocity magnitude $|u|=\sqrt{u_{x}^{2}+u_{y}^{2}}$ contours obtained from experiments [11] and LES, respectively $(J=8.7)$. Experimental and LES jet equivalence ratios are both $\phi=1.2$. Non-reactive and reactive results are presented in the left and the right part of the figure, respectively. In each of the four fields, the isolines show streamlines originating at the windward jet edge (left isolines), the center of the jet, and the leeward jet edge (right isolines). Results from experiment and LES are in good agreement. Both show a low-velocity region just upstream of the windward streamline for the non-reacting and reacting case. The low flow velocity region in the wake of the jet increases for the reactive case for experiment and LES. Figure $6 \mathrm{c}$ shows the velocity magnitude $\left|u_{y}\right|$ along the $y$-coordinate of the jet-center trajectory, which is highlighted by an arrow in (a). For the non-reactive case, $\left|u_{y}\right|$ is slightly under-predicted close to jet exit and over-predicted for $\left.(y / d)\right|_{\text {trajec }}>1$. For the reactive case, the velocity is slightly under-predicted by LES between $1.5 \leq\left.(y / d)\right|_{\text {trajec }} \leq 2.5$. However, the correct divergence of streamlines in the reacting flow due to gas expansion in the combustion products was correctly reproduced.

Figure 7 compares instantaneous snapshots from experiments (left) and LES (right) showing a zoom of the windward side of the jet. The LES snapshot was arbitrarily chosen from the simulated sequence and resemble the experimental data presented in [10]. Contours of velocity magnitude $|u|$, vorticity $\omega_{z}$, formaldehyde $\mathrm{CH}_{2} \mathrm{O}$, hydroxide $\mathrm{OH}$ and the product of the two $\mathrm{OH} \times \mathrm{CH}_{2} \mathrm{O}$ are presented from top to bottom. Species distributions from experiments were obtained from planar laserinduced fluorescence (PLIF); one can refer to [9-11] for a detailed description of PLIF measurements and PLIF image post-processing. Species from LES are given in mass fraction. For $J=5.2$, experimental fields were only available for $\phi=1.0$ and LES were only performed at $\phi=1.2$. However, typical flame dynamics were reported independent of $\phi$ [11]. Therefore, the difference is acceptable for the purpose of comparing dynamics. For all others figures, experimental and numerical $\phi$ are identical though. Wagner et al. [9-11] defined three distinct flame regions: (i) a preheat zone, (ii) a reaction zone and (iii) a post-flame zone. Zone (i) is located close to the cold premixed jet and only $\mathrm{CH}_{2} \mathrm{O}$ is present. In (ii), $\mathrm{CH}_{2} \mathrm{O}$ and $\mathrm{OH}$ overlap; this zone is tracked by $\mathrm{OH} \times \mathrm{CH}_{2} \mathrm{O}$. Zone (iii) is located close to the hot crossflow and only $\mathrm{OH}$ is present. In Fig. 7, the flame front (ii) is highlighted with black isolines at $\mathrm{OH} \times \mathrm{CH}_{2} \mathrm{O}=3 \times 10^{-8}$. This instant shows a characteristic interaction of the flame with a coherent structure of the flow (highlighted with boxes): the preheat zone (i) is thickened by a vortical structure that is visible in both $\omega_{z}$ contours, and the flame front is rolled up by this vortex. 


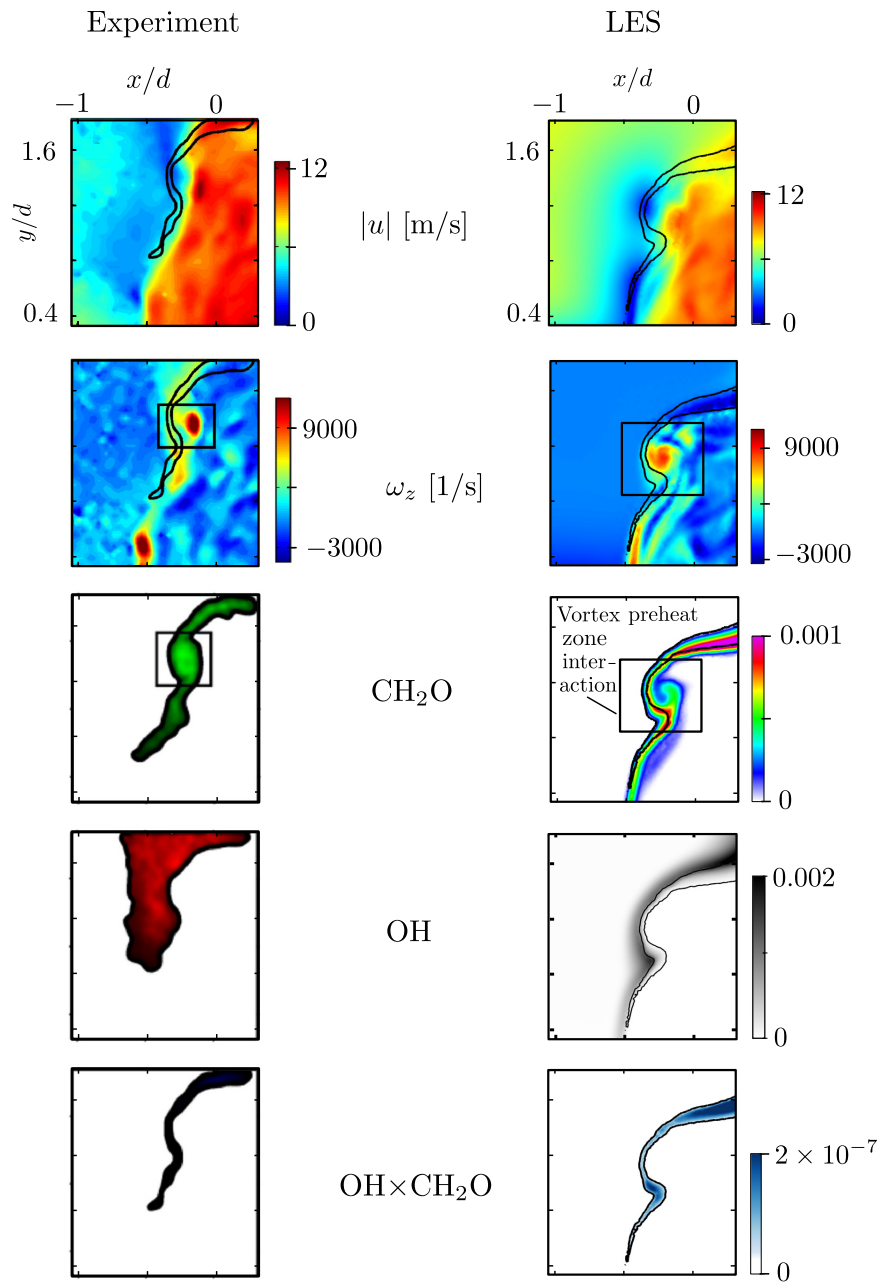

Fig. 7. Comparison between experiments (left) and LES (right). Instantaneous contours of velocity magnitude $|u|=\sqrt{u_{x}^{2}+u_{y}^{2}}$, vorticity $\omega_{z}, \mathrm{CH}_{2} \mathrm{O}, \mathrm{OH}$, and the product of the two $\mathrm{OH} \times \mathrm{CH}_{2} \mathrm{O}$, used as a flame front marker in the experiments [9-11]. $\mathrm{OH}, \mathrm{CH}_{2} \mathrm{O}$ and $\mathrm{OH} \times \mathrm{CH}_{2} \mathrm{O}$ from experiments obtained with PLIF; species from LES in mass fraction. Isolines at $\mathrm{OH} \times \mathrm{CH}_{2} \mathrm{O}=3 \times 10^{-8}$ show flame front. Jet-tocrossflow momentum ratio $J=5.2$.

\section{Flame dynamics}

Figure 8 shows seven instantaneous snapshots of a continuous sequence in a 2-D $x$-y-cut through the jet centerline with $\Delta t=0.3 \mathrm{~ms}$. Hydroxyl $(\mathrm{OH})$ mass fraction, temperature $T$ and velocity magnitude $|u|$ are presented from top to bottom. The flame is visualized by a heat release rate $\dot{q}$ isoline at $1.6 \times 10^{9} \mathrm{~W} / \mathrm{m}^{3}$. On the leeward side, the flame is attached more robustly compared to the windward side. The flame root is located near the shear layer very close to the fuel exit. It propagates into the bulk flow of the jet further downstream. This is in very good agreement with experimental results that showed a leeward flame stabilized by flame propagation [9-11]. In contrast, the lifted windward flame exhibits a significantly more complex behavior. $\mathrm{OH}$ contours on the windward side show a very thin concentration spanning from the jet exit to the flame tip (see $t_{0}$ ); this was observed for all snapshots of the entire simulation. $\mathrm{OH}$ is an important species in autoignition layers prior to flame stabilization [48]. This thin $\mathrm{OH}$ layer can be associated with radical build-up prior to autoignition. Indeed, the temperature increases upstream of the flame front close to this thin reaction zone, as shown in the zoom of the $T$ contour at $t_{0}+\Delta t$. The velocity magnitude snapshots show that this autoignition layer is located close to the shear layer between jet and crossflow. This is in agreement with results from Wagner et al. [9], proposing flame stabilization due to autoignition in the shear layer of the windward jet. The most upstream point of the windward flame base is referred to as "autoignition flame base", marked with circles at $t_{0}+\Delta t$ and $t_{0}+2 \Delta t$ in the $|u|$ contour. As highlighted from $t_{0}+3 \Delta t$ to $t_{0}+5 \Delta t$, the upstream part of the windward flame propagates into the bulk jet, which was also reported in the experiment, as shown in the top left part of Fig. 7. Finally, the two flame fronts merge at $t_{0}+6 \Delta t$, creating an isolated propagating flame front.

Figure 9 shows the time evolution of the windward and leeward flame base heights. The dashed lines highlight the timeaveraged flame positions for the leeward $\left(y_{\text {flame }} / d \approx 0.3\right)$ and windward side $\left(y_{\text {flame }} / d \approx 1.1\right)$. The positions are in good agreement with experiments [11] that showed leeward and windward flame heights of approximately 0.21 and 0.98 . The 

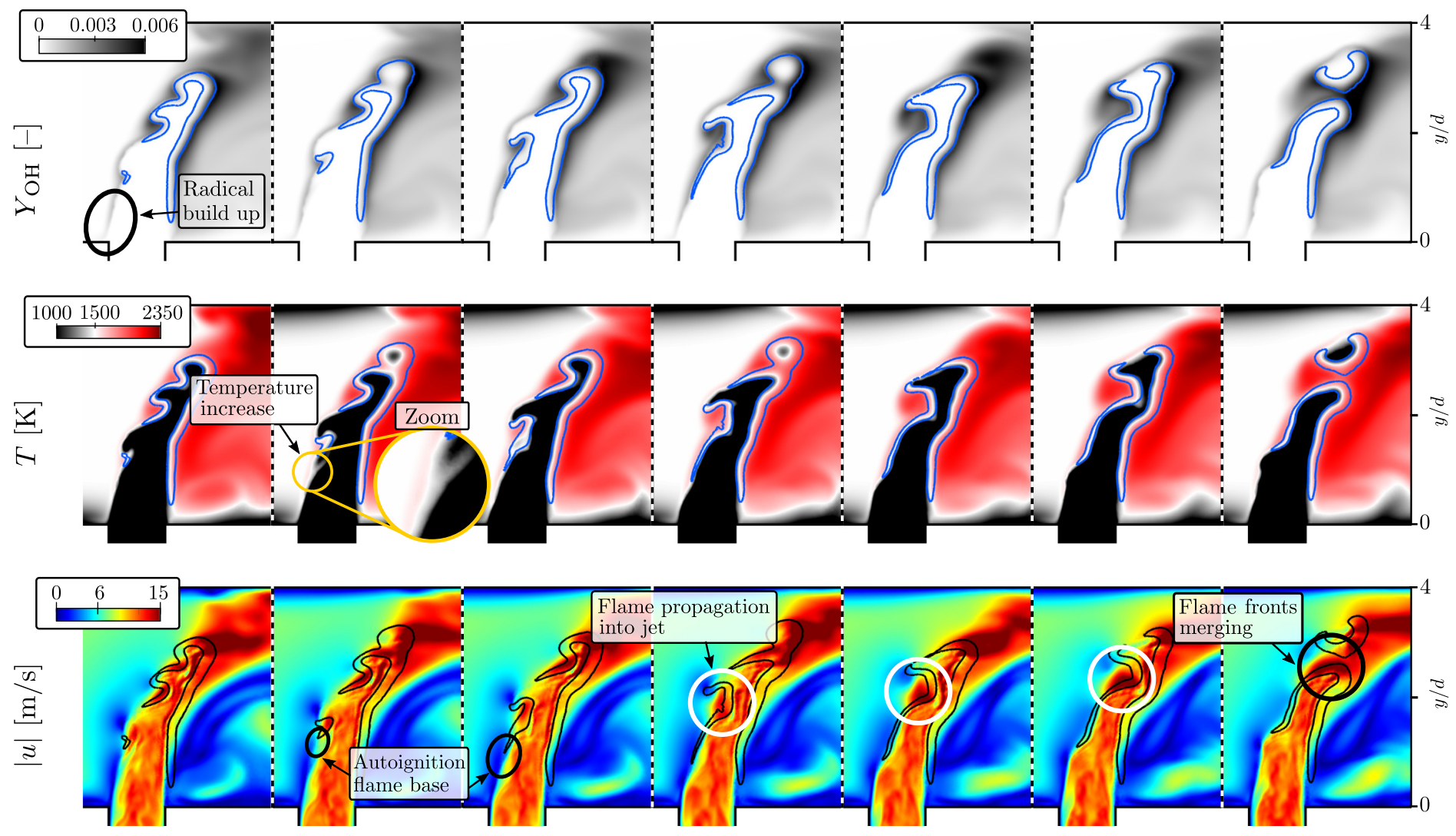

Fig. 8. An instantaneous sequence in a 2-D $x$ - $y$-cut trough jet centerline, visualizing from top to bottom: $\mathrm{OH}$ mass fraction, temperature $T$ and velocity magnitude $|u|=\sqrt{u_{x}^{2}+u_{y}^{2}}$. Flame visualized by heat release rate $\dot{q}$ isoline at $1.6 \times 10^{9} \mathrm{~W} / \mathrm{m}^{3}$. The time between snapshots is $\Delta t=0.3 \mathrm{~ms}$. Jet-to-crossflow momentum ratio $J=8.7$.

inset of Fig. 9 shows an instantaneous snapshot of $\mathrm{OH}$ (gray contour), flame front (blue isoline at $\dot{q}=1.6 \times 10^{9} \mathrm{~W} / \mathrm{m}^{3}$ ), windward flame base (green dot) and leeward flame base (red dot). The flame base height $y_{\text {flame }}$ is defined as the flame front at minimum $y$. The leeward flame base varies only slightly around its mean height. The windward flame, on the contrary, shows a strong intermittent behavior: the flame height slowly increases, followed by an abrupt shift of the flame base to lower $y_{\text {flame }}$. These sudden shifts are due to autoignition events. The windward flame front is constantly convected downstream and is intermittently "brought back" by autoignition, which governs flame stabilization on the windward side. A similar behavior was observed in [49] for a lifted methane flame in hot vitiated coflow. The authors reported "sudden jumps" in flame lift-off height associated with autoignition of mixtures located upstream of the "old" flame position. The solid blue line corresponds to the autoignition length $l_{\mathrm{AI}, \mathrm{mr}}$ computed with the shortest autoignition time $\tau_{\mathrm{AI}, \mathrm{mr}}$ and the bulk jet velocity $u_{\mathrm{j}}$. This length is one order of magnitude smaller than the time-averaged flame base height (green dashed line). This difference can be explained as follows. First, heat is released at the most reactive mixture fraction $Z_{\mathrm{mr}}$, which is located on the oxidizer side $(Z=0.1$, see Fig. 2a). This results in low heat release that can be observed close to the jet exit (see Fig. 4) and that matches with the $l_{\mathrm{AI}, \mathrm{mr}}$. Of course, such small heat release rates are difficult or even not possible to detect in the experiment, but in LES. It is expected that the heat released at $Z_{\mathrm{mr}}$ rises the temperature of neighboring richer mixtures which become the most reactive ones and eventually auto-ignite. Once higher $Z$ start to auto-ignite and significant heat is released, the flame becomes "visible" and appears lifted on the windward side. The detailed underlying mechanism will be investigated in future work.

\section{Conclusion and outlook}

This numerical paper analyzes an RJICF with a premixed ethylene-air jet at $\phi=1.2$ and $T=300 \mathrm{~K}$ injected into a hot vitiated crossflow at $1500 \mathrm{~K}$. The RJICF was recently investigated experimentally by Wagner et al. [9-11] proposing autoignition and flame propagating as dominant flame stabilization mechanisms. The present study is a follow up of this 


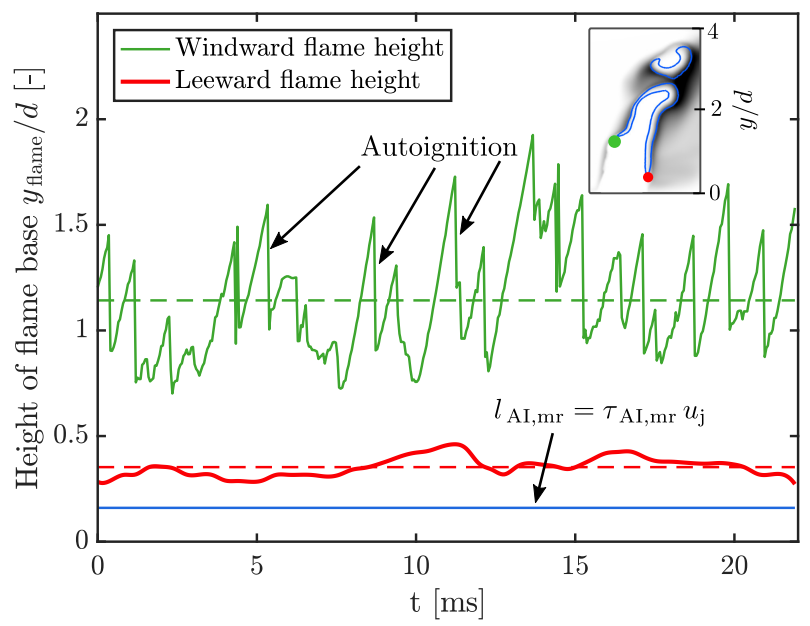

Fig. 9. Time evolution of windward and leeward flame heights $y_{\text {flame. }}$. Dashed lines show average $y_{\text {flame. The inset shows an instantaneous }}$ snapshot of $\mathrm{OH}$ contour, the flame front highlighted by isolines, and the two flame bases. The blue line shows autoignition length computed with $\tau_{\mathrm{AI}, \mathrm{mr}}$ at $Z_{\mathrm{mr}}$ and the jet bulk velocity. $J=8.7$.

experimental work and aims at bringing more insight into the flame dynamics and the complex stabilization mechanism by the use of 3-D LES in combination with ARC and the DTF model.

First, 0-D and 1-D Cantera simulations compare two chemical mechanisms for ethylene-air combustion: (i) a detailed mechanism and (ii) the ARC mechanism used in this study. ARC is in excellent agreement with detailed chemistry and captures the non-trivial autoignition chemistry associated with radical build-up prior to ignition. Moreover, the effect of the DTF model on autoignition is investigated for varying grid sizes $\Delta x$ and mixture compositions. The model has no impact on autoignition times for the characteristic $\Delta x$ used in this study. However, the model can significantly delay autoignition for bigger $\Delta x$. Second, results from LES are compared to experiments. 2-D time-averaged velocity fields and jet trajectories are in very good agreement for non-reactive and reactive simulations. Moreover, LES successfully reproduce characteristic flame-vortex interactions.

Finally, a dynamic flame analysis is presented. It shows a leeward flame that is anchored stably in the shear layer close to the jet exit. Further downstream, the flame transverses the shear layer and propagates into the bulk jet containing a flammable mixture. The windward flame, in contrast, shows a much stronger dynamic behavior. The lifted flame base is shifted downstream and is "brought back" by autoignition intermittently. These autoignition events occur close to a thin layer of $\mathrm{OH}$ radicals that spans over the entire windward side down to the jet exit for all instants of time. Further downstream, the windward flame can also propagate into the bulk jet leading to flame fronts merging with the leeward flame inside the jet. The understanding of flame dynamics and flame stabilization can be particularly important for practical applications, such as combustion systems in stationary gas turbines. In such systems, the dynamic flame behavior has a strong influence on the thermoacoustic stability [50,51]. Recently, it was shown that temperature fluctuations of the crossflow can lead to very strong spatial fluctuations of the heat release rate zone due to a modulation of the autoignition time of the mixtures. The resulting heat release rate fluctuations depend on the mean crossflow temperature, as shown in [33]. These results were obtained in conditions similar to the present one. Therefore, future work could address the effect of upstream temperature fluctuations on these particular RJICF flame dynamics.

\section{Acknowledgements}

This research is supported by the Swiss National Science Foundation under Grant 160579. The work is also supported by a grant from the Swiss National Supercomputing Centre (CSCS) under project ID s685. The authors gratefully acknowledge CERFACS for providing the LES solver AVBP. We especially thank A. Felden for providing the ARC mechanism and G. Staffelbach for the AVBP technical support. The authors also thank P. Pepiot for providing the YARC reduction tool.

\section{References}

[1] Sutton, G. O., 1932. "A theory of eddy diffusion in the atmosphere". Proceedings of the Royal Society of London. Series A, Containing Papers of a Mathematical and Physical Character, 135(826), pp. 143-165.

[2] Margason, R. J., 1993. "Fifty years of jet in cross flow research". In Proceedings of the AGARD Symposium on 
Computational and Experimental Assessment of Jets in Crossflow, Winchester, UK, No. AGARD-CP-534, Vol. 1, pp. $1-41$.

[3] Foust, M., Thomsen, D., Stickles, R., Cooper, C., and Dodds, W., 2012. "Development of the GE aviation low emissions TAPS combustor for next generation aircraft engines". 50th AIAA Aerospace Sciences Meeting including the New Horizons Forum and Aerospace Exposition(January), pp. 1-9.

[4] Pennell, D. A., Bothien, M. R., Ciani, A., Granet, V., Singla, G., Thorpe, S., and Wickstroem, A., 2017. “An introduction to the Ansaldo GT36 constant pressure sequential combustor". ASME Turbo Expo GT2017-64790.

[5] Mahesh, K., 2013. "The interaction of jets with crossflow". Annual Review of Fluid Mechanics, 45(1), pp. 379-407.

[6] Karim, H., Natarajan, J., Narra, V., Cai, J., Rao, S., Kegley, J., and Citeno, J., 2017. "Staged combustion system for improved emissions operability \& flexibility for 7HA class heavy duty gas turbine engine". ASME Turbo Expo GT2017-63998.

[7] Hoehne, V., and Luce, R., 1970. "Effect of velocity, temperature, and molecular weight on flammability limits in wind-blown jets of hydrocarbon gases.". Proc., Am. Pet. Inst., Sect. 3; 50.

[8] Brzustowski, T. A., Gollahalli, S. R., and Sullivan, H. F., 1975. "The turbulent hydrogen diffusion flame in a crosswind". Combustion Science and Technology, 11(1-2), pp. 29-33.

[9] Wagner, J., Renfro, M., and Cetegen, B., 2017. "Premixed jet flame behavior in a hot vitiated crossflow of lean combustion products". Combustion and Flame, 176, pp. 521-533.

[10] Wagner, J. A., Grib, S. W., Dayton, J. W., Renfro, M. W., and Cetegen, B. M., 2017. "Flame stabilization analysis of a premixed reacting jet in vitiated". Proceedings of the Combustion Institute, 36, pp. 3763-3771.

[11] Wagner, J. A., Grib, S. W., Renfro, M. W., and Cetegen, B. M., 2015. "Flowfield measurements and flame stabilization of a premixed reacting jet in vitiated crossflow". Combustion and Flame, 162(10), pp. 3711-3727.

[12] Hunt, J. C. R., Wray, A. A., and Moin, P., 1988. "Eddies, streams, and convergence zones in turbulent flows". In Center for Turbulence Research, Proceedings of the Summer Program, no. 1970, pp. 193-208.

[13] Schmitt, D., Kolb, M., Weinzierl, J., Hirsch, C., and Sattelmayer, T., 2013. "Ignition and flame stabilization of a premixed jet in hot cross flow". In ASME Turbo Expo, pp. 2013-94763.

[14] Kolb, M., Ahrens, D., Hirsch, C., and Sattelmayer, T., 2016. "A model for predicting the lift-off height of premixed jets in vitiated cross flow". J. Eng. Gas Turbines Power, 138(8), p. 081901.

[15] Kalghatgi, G. T., 1983. "The visible shape and size of a turbulent hydrocarbon jet diffusion flame in a cross-wind". Combustion and Flame, 52(C), pp. 91-106.

[16] Boutazakhti, M., Thomson, M. J., and Lightstone, M., 2001. "The effect of jet mixing on the combustion efficiency of a hot fuel-rich cross-flow". Combustion Science and Technology, 163(1), pp. 211-228.

[17] Grout, R. W., Gruber, A., Kolla, H., Bremer, P. T., Bennett, J. C., Gyulassy, A., and Chen, J. H., 2012. "A direct numerical simulation study of turbulence and flame structure in transverse jets analysed in jet-trajectory based coordinates". Journal of Fluid Mechanics, 706(2012), pp. 351-383.

[18] Lyra, S., Wilde, B., Kolla, H., Seitzman, J. M., Lieuwen, T. C., and Chen, J. H., 2015. "Structure of hydrogen-rich transverse jets in a vitiated turbulent flow". Combustion and Flame, 162(4), pp. 1234-1248.

[19] Schulz, O., Doll, U., Ebi, D., Droujko, J., Bourquard, C., and Noiray, N., 2018. "Thermoacoustic instability in a sequential combustor: large eddy simulation and experiments". accepted Proc. Combust. Inst. 37.

[20] Sullivan, R., Wilde, B., Noble, D. R., Seitzman, J. M., and Lieuwen, T. C., 2014. "Time-averaged characteristics of a reacting fuel jet in vitiated cross-flow". Combustion and Flame, 161(7), pp. 1792-1803.

[21] Fleck, J. M., Griebel, P., Steinberg, A. M., Arndt, C. M., Naumann, C., and Aigner, M., 2013. "Autoignition of hydrogen/nitrogen jets in vitiated air crossflows at different pressures". Proceedings of the Combustion Institute, 34(2), pp. 3185-3192.

[22] Micka, D. J., and Driscoll, J. F., 2012. "Stratified jet flames in a heated (1390K) air cross-flow with autoignition". Combustion and Flame, 159(3), pp. 1205-1214.

[23] Arndt, C. M., Papageorge, M. J., Fuest, F., Sutton, J. A., Meier, W., and Aigner, M., 2016. "The role of temperature, mixture fraction, and scalar dissipation rate on transient methane injection and auto-ignition in a jet in hot coflow burner". Combustion and Flame, 167, pp. 60-71.

[24] Mastorakos, E., Baritaud, T. A., and Poinsot, T. J., 1997. "Numerical simulations of autoignition in turbulent mixing flows". Combustion and Flame, 109(1-2), pp. 198-223.

[25] Schulz, O., Jaravel, T., Poinsot, T., Cuenot, B., and Noiray, N., 2017. "A criterion to distinguish autoignition and propagation applied to a lifted methane-air jet flame". Proceedings of the Combustion Institute, 36(2), pp. 1637-1644.

[26] Weinzierl, J., Kolb, M., Ahrens, D., Hirsch, C., and Sattelmayer, T., 2016. "Large eddy simulation of a reacting jet in cross flow with NOx prediction”. J. Eng. Gas Turbines Power, 139(3), p. 031502.

[27] Schlegel, F., and Ghoniem, A. F., 2014. "Simulation of a high Reynolds number reactive transverse jet and the formation of a triple flame". Combustion and Flame, 161(4), pp. 971-986.

[28] Fiorina, B., Veynante, D., and Candel, S., 2014. "Modeling Combustion Chemistry in Large Eddy Simulation of Turbulent Flames". Flow, Turbulence and Combustion, pp. 3-42. 
[29] Selle, L., Lartigue, G., Poinsot, T., Koch, R., Schildmacher, K. U., Krebs, W., Prade, B., Kaufmann, P., and Veynante, D., 2004. "Compressible large eddy simulation of turbulent combustion in complex geometry on unstructured meshes". Combustion and Flame, 137(4), pp. 489-505.

[30] Heinz, C., M., B., and Polifke, W., 2005. "Optimization of rate coefficients for global reaction mechanisms using a nested genetic algorithm". Proceedings of the European Combustion meeting(January 2005).

[31] Peters, N., 1984. Laminar diffusion flamelet models in non-premixed turbulent combustion.

[32] Kulkarni, R., Zellhuber, M., and Polifke, W., 2013. "LES based investigation of autoignition in turbulent co-flow configurations". Combustion Theory and Modelling, 17(2), pp. 224-259.

[33] Schulz, O., and Noiray, N., 2018. "Autoignition flame dynamics in sequential combustors". Combustion and Flame, 192, pp. 86-100.

[34] Scarpato, A., Zander, L., Kulkarni, R., and Schuermans, B., 2016. "Identification of multi-parameter flame transfer function for a reheat combustor". ASME Turbo Expo GT2016-57699.

[35] Felden, A., Cuenot, B., and Riber, E., 2018. "Impact of direct integration of Analytically Reduced Chemistry in LES of a sooting swirled non-premixed combustor". Combustion and Flame, 191, pp. 270-286.

[36] Jaravel, T., Riber, E., Cuenot, B., and Pepiot, P., 2018. "Prediction of flame structure and pollutant formation of Sandia flame D using Large Eddy Simulation with direct integration of chemical kinetics". Combustion and Flame, 188, pp. 180-198.

[37] Narayanaswamy, K., Pepiot, P., and Pitsch, H., 2014. "A chemical mechanism for low to high temperature oxidation of n-dodecane as a component of transportation fuel surrogates". Combustion and Flame, 161(4), pp. 866-884.

[38] Goodwin, D. G., Moffat, H. K., and Speth, R. L., 2017. "Cantera: An object-oriented software toolkit for chemical kinetics, thermodynamics, and transport processes". http://www.cantera.org.

[39] Pepiot-Desjardins, P., and Pitsch, H., 2008. "An efficient error-propagation-based reduction method for large chemical kinetic mechanisms". Combustion and Flame, 154(1-2), pp. 67-81.

[40] Pepiot-Desjardins, P., and Pitsch, H., 2008. "An automatic chemical lumping method for the reduction of large chemical kinetic mechanisms". Combustion Theory and Modelling, 12(6), pp. 1089-1108.

[41] Gicquel, L. Y. M., Gourdain, N., Boussuge, J. F., Deniau, H., Staffelbach, G., Wolf, P., and Poinsot, T., 2011. "High performance parallel computing of flows in complex geometries". Comptes Rendus - Mecanique, 339(2-3), pp. 104124.

[42] Colin, O., and Rudgyard, M., 2000. "Development of High-Order TaylorGalerkin Schemes for LES". Journal of Computational Physics, 162(2), pp. 338-371.

[43] Pope, S. B., 2000. Turbulent flows. Cambridge University Press.

[44] van Driest, E. R., 2003. “Turbulent Boundary Layer in Compressible Fluids”. Journal of Spacecraft and Rockets, 40(6), pp. 1012-1028.

[45] Schmitt, P., Poinsot, T., Schuermans, B., and Geigle, K. P., 2007. "Large-eddy simulation and experimental study of heat transfer, nitric oxide emissions and combustion instability in a swirled turbulent high-pressure burner". Journal of Fluid Mechanics, 570, p. 17.

[46] Colin, O., Ducros, F., Veynante, D., and Poinsot, T., 2000. "A thickened flame model for large eddy simulations of turbulent premixed combustion". Physics of Fluids, 12(7), pp. 1843-1863.

[47] Deardorff, J. W., 1980. "Stratocumulus-capped mixed layers derived from a three-dimensional model". BoundaryLayer Meteorology, 18(4), pp. 495-527.

[48] Luo, Z., Yoo, C. S., Richardson, E. S., Chen, J. H., Law, C. K., and Lu, T., 2012. "Chemical explosive mode analysis for a turbulent lifted ethylene jet flame in highly-heated coflow". Combustion and Flame, 159(1), pp. $265-274$.

[49] Navarro-Martinez, S., and Kronenburg, a., 2009. "LES-CMC simulations of a lifted methane flame". Proceedings of the Combustion Institute, 32 I, pp. 1509-1516.

[50] Zinn, B. T., and Lieuwen, T. C., 2005. Combustion instabilities: basic concepts. in: Combustion instabilities in gas turbine engines, T. C. Lieuwen and V. Yang (Eds.), Progress in Astronautics and Aeronautics, Vol. 210. American Institute of Aeronautics and Astronautics, Reston, VA.

[51] Poinsot, T., 2017. "Prediction and control of combustion instabilities in real engines". Proceedings of the Combustion Institute, 36(1), pp. 1-28. 